Article

\title{
Optimal Design for Reactivity Ratio Estimation: A Comparison of Techniques for AMPS/Acrylamide and AMPS/Acrylic Acid Copolymerizations
}

\author{
Alison J. Scott, Marzieh Riahinezhad and Alexander Penlidis * \\ Institute for Polymer Research (IPR), Department of Chemical Engineering, University of Waterloo, \\ Waterloo, ON N2L 3G1, Canada; E-Mails: ajscott@uwaterloo.ca (A.J.S.); \\ marzieh.riahinezhad@uwaterloo.ca (M.R.)
}

* Author to whom correspondence should be addressed; E-Mail: penlidis@uwaterloo.ca; Tel.: +1-519-888-4567 (ext. 36634).

Academic Editor: Masoud Soroush

Received: 15 July 2015 / Accepted: 30 October 2015 / Published: 10 November 2015

\begin{abstract}
Water-soluble polymers of acrylamide (AAm) and acrylic acid (AAc) have significant potential in enhanced oil recovery, as well as in other specialty applications. To improve the shear strength of the polymer, a third comonomer, 2-acrylamido-2-methylpropane sulfonic acid (AMPS), can be added to the pre-polymerization mixture. Copolymerization kinetics of AAm/AAc are well studied, but little is known about the other comonomer pairs (AMPS/AAm and AMPS/AAc). Hence, reactivity ratios for AMPS/AAm and AMPS/AAc copolymerization must be established first. A key aspect in the estimation of reliable reactivity ratios is design of experiments, which minimizes the number of experiments and provides increased information content (resulting in more precise parameter estimates). However, design of experiments is hardly ever used during copolymerization parameter estimation schemes. In the current work, copolymerization experiments for both AMPS/AAm and AMPS/AAc are designed using two optimal techniques (Tidwell-Mortimer and the error-in-variables-model (EVM)). From these optimally designed experiments, accurate reactivity ratio estimates are determined for AMPS/AAm $\left(\mathrm{r}_{\mathrm{AMPS}}=0.18, \mathrm{r}_{\mathrm{AAm}}=0.85\right)$ and AMPS/AAc $\left(\mathrm{r}_{\mathrm{AMPS}}=0.19, \mathrm{r}_{\mathrm{AAc}}=0.86\right)$.
\end{abstract}

Keywords: acrylamide; acrylic acid; 2-acrylamido-2-methylpropane sulfonic acid; copolymerization; design of experiments; reactivity ratio estimation 


\section{Introduction}

Some of the most common acrylamide-based copolymer systems used in enhanced oil recovery (EOR) are acrylamide (AAm) and acrylic acid (AAc) copolymers. However, these AAm/AAc copolymers, like many other water-soluble polymers with high molecular weights, are very shear sensitive. That is, when the copolymer is subjected to high temperatures and stresses, there is potential for the polymer backbone to break [1]. This directly affects the polymer's efficiency in enhanced oil recovery, as the polymer in this case will not be able to increase the aqueous phase viscosity as much as was originally desired. Thus, it is essential to minimize polymer degradation in EOR applications.

2-acrylamido-2-methylpropane sulfonic acid (AMPS) has the potential to improve main chain stability in harsh environments. The steric hindrance provided by the sulfonic group in AMPS is expected to control potential degradation of the polymer backbone [2], enhance thermal stability [3], and improve the polymer's resistance to precipitation by limiting hydrolysis [4]. A survey of existing (yet unreliable) reactivity ratios in the literature for the related copolymers (AMPS/AAm and AMPS/AAc) confirms that synthesis and testing of the AMPS/AAm/AAc terpolymer is promising. To tailor-make a water-soluble terpolymer of AMPS/AAm/AAc, polymerization kinetics for the binary components must first be understood. AAm/AAc copolymerization kinetics have recently been clarified [5], so the current study focuses on AMPS/AAm and AMPS/AAc.

The statistically correct error-in-variables-model (EVM) is used for analysis, as it is a non-linear estimation technique that considers the error present in all variables [6,7]. Through EVM and direct numerical model integration, we are also able to estimate reactivity ratios using cumulative composition data (as opposed to standard analysis of low-conversion data). This provides additional advantages, including eliminating unnecessary assumptions and avoiding the experimental challenges associated with collecting low-conversion data [8]. Copolymerizations of both AMPS/AAm and AMPS/AAc are designed using Tidwell-Mortimer (T-M) and error-in-variables-model (EVM) techniques. Reactivity ratios (and associated joint confidence regions) obtained through the traditional T-M design are contrasted with those obtained through EVM design. This allows for a direct comparison between the T-M and EVM design approaches (not readily available in the literature).

\subsection{Copolymerization Kinetics}

The Mayo-Lewis model is widely used for copolymerization systems. This classical equation, also called the instantaneous copolymer composition equation, is presented in Equation (1).

$$
\frac{\mathrm{d}\left[\mathrm{M}_{1}\right]}{\mathrm{d}\left[\mathrm{M}_{2}\right]}=\left(\frac{\left[\mathrm{M}_{1}\right]}{\left[\mathrm{M}_{2}\right]}\right)\left(\frac{\mathrm{r}_{1}\left[\mathrm{M}_{1}\right]+\left[\mathrm{M}_{2}\right]}{\left[\mathrm{M}_{1}\right]+\mathrm{r}_{2}\left[\mathrm{M}_{2}\right]}\right)
$$

where $\left[\mathrm{M}_{1}\right]$ and $\left[\mathrm{M}_{2}\right]$ are the concentrations of monomer 1 and 2 in the polymerizing mixture, and

$$
\mathrm{r}_{1}=\frac{\mathrm{k}_{\mathrm{p} 11}}{\mathrm{k}_{\mathrm{p} 12}} \text { and } \mathrm{r}_{2}=\frac{\mathrm{k}_{\mathrm{p} 22}}{\mathrm{k}_{\mathrm{p} 21}}
$$

The monomer reactivity ratios, $r_{1}$ and $r_{2}$, describe the potential for homo-propagation relative to cross-propagation. These parameters are specific to each copolymer system, and many summary tables are available citing reactivity ratios of common copolymer systems [9]. Reactivity ratios can be 
estimated using experimental data, if the free (unreacted) monomer composition in the polymerizing mixture and the bound (incorporated) monomer composition in the polymer chains (i.e., copolymer composition) are known.

Another popular form of the copolymerization equation (Equation (1)) is given by Equation (3), which provides information directly about the instantaneous composition of the copolymer, $\mathrm{F}_{1}$, given the comonomer composition in the polymerizing mixture.

$$
F_{1}=\frac{r_{1} f_{1}^{2}+f_{1} f_{2}}{r_{1} f_{1}^{2}+2 f_{1} f_{2}+r_{2} f_{2}^{2}}
$$

where $f_{1}$ and $f_{2}$ represent the mole fractions of unreacted monomer 1 and monomer 2 in the polymerizing mixture. $F_{1}$ is the instantaneous mole fraction of monomer 1 units bound (incorporated) in the copolymer chains, corresponding to $\mathrm{f}_{1}$.

An additional point of interest in copolymerization kinetics is establishing the azeotropic composition (if it exists) for the system. At the azeotropic point, the feed composition $\left(\mathrm{f}_{1}\right)$ and the instantaneous copolymer composition $\left(\mathrm{F}_{1}\right)$ are equivalent. If the reactivity ratios are known, we can use the instantaneous copolymerization equation (Equation (3)) to examine $F_{1}$ as a function of $f_{1}$ and to establish the azeotropic point. By setting $F_{1}=f_{1}$, Equation (3) is simplified to the binary azeotropic composition, shown in Equation (4) [10].

$$
\mathrm{F}_{1}=\mathrm{f}_{1}=\frac{1-\mathrm{r}_{2}}{2-\mathrm{r}_{1}-\mathrm{r}_{2}}
$$

Determination of azeotropic composition is just one application for reactivity ratios, which are extremely important parameters for copolymerization kinetics. Reactivity ratios can also be used to predict polymer properties such as copolymer composition or sequence length, and could eventually be used in custom polymer production for specific applications [11]. Therefore, it is essential that reactivity ratio estimates be as accurate as possible. Techniques for reactivity ratio estimation are briefly discussed in what follows.

\subsection{Reactivity Ratio Estimation}

In general, reactivity ratios are parameters obtained from experimental data by analyzing the copolymer composition at several different feed compositions. Traditionally, linear regression techniques have incorrectly been used for reactivity ratio estimation. These techniques include the Mayo-Lewis method (method of intersections), the Fineman-Ross method and the Kelen-Tudos method [12]. These techniques were originally chosen for their simplicity, as technology was not readily available for intense computation. However, linearizing the kinetic models (which are inherently non-linear in the parameters) requires making imprecise, subjective and invalid assumptions. An additional consideration is the use of the instantaneous copolymerization model in these linear techniques; the reaction must be kept at low conversion so that the assumption of "constant composition" in the feed is somewhat valid [8]. However, polymerizations at low conversions are extremely error-prone, and it is impossible to guarantee that the feed composition will remain constant (especially when dealing with an unstudied system). 


\subsection{Design of Experiments}

Optimal design of experiments leads to increased information content while minimizing the number of experiments and obtaining more precise parameter estimates [7]. Tidwell and Mortimer [13] applied an (approximate) D-optimality criterion to the Mayo-Lewis copolymerization equation to determine the best monomer feed compositions at which to run reactivity ratio estimation experiments:

$$
\mathrm{f}_{2,1}=\frac{\mathrm{r}_{1}}{2+\mathrm{r}_{1}} \quad \text { and } \quad \mathrm{f}_{2,2}=\frac{2}{2+\mathrm{r}_{2}}
$$

where $f_{2,1}$ and $f_{2,2}$ denote the initial feed composition of monomer 2 for the first and second experiments, respectively. Preliminary reactivity ratio estimates $\left(r_{1}\right.$ and $\left.r_{2}\right)$ can be obtained from the literature or from some type of preliminary experimentation.

D-optimality is an extremely powerful criterion, and through its "ease-of-use" it can act as a good starting point for experimental design. A more complex, yet equally valid, technique for designing optimal reactivity ratio estimation experiments is the error-in-variables-model (EVM) [14]. EVM is not only used for reactivity ratio estimation, but also employed in the preceding design of experiments stage; the technique considers error terms in all variables involved (both independent and dependent) in the process model.

\section{Experimental}

\subsection{Reagent Purification}

Monomers 2-acrylamido-2-methylpropane sulfonic acid (AMPS; 99\%), acrylamide (AAm; electrophoresis grade, 99\%), and acrylic acid (AAc; 99\%) were purchased from Sigma-Aldrich (Oakville, ON, Canada). AAc was purified via vacuum distillation at $30{ }^{\circ} \mathrm{C}$, while AAm and AMPS were used as received. Initiator (4,4'-azo-bis-(4-cyanovaleric acid), ACVA), inhibitor (hydroquinone) and sodium hydroxide were also purchased from Sigma-Aldrich. Sodium chloride from EMD Millipore (Etobicoke, ON, Canada) was used as received. In terms of solvents, water was Millipore quality (18 M $\Omega \cdot \mathrm{cm})$; acetone (99\%) and methanol (99.8\%) were used as received from suppliers. Nitrogen gas (4.8 grade) used for degassing solutions was purchased from Praxair (Mississauga, ON, Canada).

\subsection{Polymer Synthesis}

In general, the experimental techniques described by Riahinezhad et al. [5] were adopted for these copolymer systems. Monomer solutions with a total monomer concentration of $1 \mathrm{M}$ were prepared. The comonomer ratios in each system (AMPS/AAm and AMPS/AAc) are described in detail later as part of the experimental design for each individual system. The monomer solutions were titrated with sodium hydroxide to adjust the $\mathrm{pH}$ to approximately $7( \pm 0.5)$. Each recipe had $0.004 \mathrm{M}$ initiator (ACVA), and sodium chloride was added to ensure constant ionic strength among the experiments. Constant $\mathrm{pH}$ and ionic strength are extremely important in copolymer and terpolymer synthesis, as has been demonstrated previously [15]. The solutions were then purged with $200 \mathrm{~mL} / \mathrm{min}$ nitrogen for $2 \mathrm{~h}$. After degassing, aliquots of $\sim 20 \mathrm{~mL}$ of solution were transferred to sealed vials using the cannula transfer method [5]. Free-radical solution (aqueous phase) polymerizations were run in a temperature 
controlled shaker-bath (OLS200; Grant Instruments, Cambridge, UK) at $40{ }^{\circ} \mathrm{C}$ and $100 \mathrm{rpm}$. Vials were removed at selected time intervals, placed in ice and further injected with approximately $1 \mathrm{~mL}$ of $0.2 \mathrm{M}$ hydroquinone solution to stop the polymerization. Polymer samples were isolated by precipitating the products in acetone or methanol, filtered (paper filter grade number 41, Whatman; Sigma-Aldrich, Oakville, ON, Canada) and vacuum dried for 1 week at $50{ }^{\circ} \mathrm{C}$. All polymerizations were independently replicated.

\subsection{Polymer Characterization}

Conversion of the polymer samples was determined using gravimetry. The mass of the sodium ions was also considered in conversion calculations, as per the recommendation of Riahinezhad et al. [15]. Copolymer composition was measured using elemental analysis (CHNS, Vario Micro Cube, Elementar). Calculation of composition did not include $\mathrm{H}$ content, as residual water has been known to affect the determined $\mathrm{H}$ content [5]. Select samples were independently replicated.

\section{AMPS/AAm Copolymer}

\subsection{Literature Background for AMPS/AAm}

The majority of the work in the copolymerization of 2-acrylamido-2-methylpropane sulfonic acid (AMPS) with acrylamide (AAm) has focused on crosslinking systems, as crosslinked copolymers of AMPS and AAm have applications as superabsorbent hydrogels (e.g., see [16-19]). As with many other copolymer systems, such studies look at the final polymer (synthesis and characterization without considering the full conversion trajectory) and its performance properties, while they rarely investigate polymerization kinetics or reactivity ratio estimation. There has also been some work done in examining the effectiveness of AMPS/AAm copolymers in enhanced oil recovery (EOR) [2,20-22]. The focus of these articles is intended to be the synthesis and testing of polymers for EOR use.

The objective here is to obtain accurate and reliable reactivity ratios for the AMPS/AAm copolymer. Therefore, Table 1 provides a summary of reactivity ratios as reported in the literature for the copolymerization of AMPS and AAm. Although some of the estimates are similar (especially for $\mathrm{r}_{\mathrm{AAm}}$ ), there are evident inconsistencies between experimental techniques and reactivity ratio estimation methods. It is also important to note that all of the estimation techniques used to date have been linear. Given the numerous sources of error associated with linear estimation methods and the advantages of non-linear techniques, it seems only reasonable that future reactivity ratios be estimated using EVM [7]. 
Table 1. Reactivity ratio summary for AMPS/AAm.

\begin{tabular}{|c|c|c|c|c|}
\hline Ref. & Experimental & Estimation Technique & $\mathbf{r}_{\text {AMPS }}$ & $\mathbf{r}_{\mathrm{AAm}}$ \\
\hline [16] & $\begin{array}{l}\text {--Type: Aqueous solution } \\
\text { crosslinking copolymerization } \\
\text {--Initiator: KPS } \\
\text {--Temperature: } 40^{\circ} \mathrm{C} \\
\text {--pH = } 7 \\
\text {--Composition: IR and EA }\end{array}$ & $\begin{array}{l}\text { Comparison of feed and } \\
\text { copolymer compositions } \\
\text { (no statistical estimation) }\end{array}$ & 1.00 & 1.00 \\
\hline [23] & $\begin{array}{l}\text {--Type: Aqueous solution } \\
\text { copolymerization } \\
\text {--Initiator: KPS } \\
\text {--Temperature: } 50^{\circ} \mathrm{C} \\
\text {--Composition: EA }\end{array}$ & $\begin{array}{l}\text { Billmeyer * [24] } \\
\text { Billmeyer * [24] } \\
\text { Kelen-Tudos } \\
\text { Average }\end{array}$ & $\begin{array}{c}0.76 \\
0.70 \\
0.62 \\
0.70 \pm 0.08\end{array}$ & $\begin{array}{c}1.00 \\
1.06 \\
1.21 \\
1.10 \pm 0.10\end{array}$ \\
\hline [25] & $\begin{array}{l}\text {--Type: Aqueous solution } \\
\text { copolymerization } \\
\text {--Initiator: KPS } \\
\text {--Temperature: } 35^{\circ} \mathrm{C} \text { and } 55^{\circ} \mathrm{C} \\
\text {--Composition: } \mathrm{H}-\mathrm{NMR} \text { and } \\
\text { vibrational Raman spectroscopy }\end{array}$ & Fineman-Ross & 1.00 & 1.00 \\
\hline [26] & $\begin{array}{l}\text {--Type: Aqueous solution } \\
\text { copolymerization } \\
\text {--Initiator: KPS } \\
\text {--Temperature: } 30^{\circ} \mathrm{C} \\
\text {--pH = } 9 \\
\text {--Composition: IR and EA }\end{array}$ & $\begin{array}{l}\text { Fineman-Ross } \\
\text { Kelen-Tudos } \\
\text { Integrated Mayo-Lewis }\end{array}$ & $\begin{array}{l}0.49 \pm 0.02 \\
0.52 \pm 0.07 \\
0.50 \pm 0.01\end{array}$ & $\begin{array}{l}0.98 \pm 0.09 \\
1.00 \pm 0.08 \\
1.02 \pm 0.01\end{array}$ \\
\hline [27] & $\begin{array}{l}\text {--Type: Aqueous solution } \\
\text { copolymerization } \\
\text {--Initiator: APS } \\
\text {--Temperature: } 60^{\circ} \mathrm{C} \\
\text {--Composition: EA and C-NMR }\end{array}$ & $\begin{array}{l}\text { Fineman-Ross } \\
\text { Kelen-Tudos }\end{array}$ & $\begin{array}{l}0.37 \pm 0.04 \\
0.42 \pm 0.03\end{array}$ & $\begin{array}{l}1.01 \pm 0.01 \\
1.05 \pm 0.06\end{array}$ \\
\hline [27] & $\begin{array}{l}\text {--Type: Aqueous solution redox } \\
\text { copolymerization } \\
\text {--Initiator: APS/NaHSO} \\
\text {--Temperature: } 25^{\circ} \mathrm{C} \\
\text {--Composition: C-NMR } \\
\end{array}$ & $\begin{array}{l}\text { Fineman-Ross } \\
\text { Kelen-Tudos }\end{array}$ & $\begin{array}{l}0.54 \pm 0.03 \\
0.51 \pm 0.03\end{array}$ & $\begin{array}{l}1.07 \pm 0.01 \\
1.05 \pm 0.06\end{array}$ \\
\hline
\end{tabular}

Nomenclature: AAm, acrylamide; AMPS, 2-acrylamido-2-methylpropane sulfonic acid; APS, ammonium persulfate; EA, elemental analysis; IR, infrared spectroscopy; KPS, potassium persulfate; NMR, nuclear magnetic resonance; * Note: Based on estimation approaches described in Billmeyer [24].

\subsection{Design of Experiments for AMPS/AAm}

Both the Tidwell-Mortimer (T-M) and error-in-variables-model (EVM) design of experiments rely on preliminary reactivity ratio estimates. Therefore, experimental work begins with preliminary experiments, which are based on existing literature values from McCormick and Chen $\left(\mathrm{r}_{\mathrm{AMPS}}=0.50\right.$, $\left.\mathrm{r}_{\mathrm{AAm}}=1.02\right)$ [26]. Once preliminary reactivity ratio estimates are established, the T-M and EVM criteria can be used to design optimal experiments. Each experimental design provides two feed 
compositions (in terms of monomer 1; AMPS in this case) at which to run new experimental trials, and the results are presented below. In Table 2, $\mathrm{f}_{\mathrm{AmPS}, 0,1}$ represents the first initial feed composition (in terms of AMPS) from the design, just as $\mathrm{f}_{\mathrm{AMPS}, 0,2}$ represents the second initial feed composition from the design. The reactivity ratio estimates obtained from each design are also included for easy comparison. More details on the determination of reactivity ratio estimates follow.

Table 2. Design of experiments and reactivity ratio estimates for AMPS/AAm.

\begin{tabular}{ccccccc}
\hline \multirow{2}{*}{ Approach } & \multicolumn{2}{c}{ Reactivity Ratios for Design } & \multicolumn{2}{c}{ Feed Compositions (Mole Fractions) } & \multicolumn{2}{c}{ New Reactivity Ratio Estimates } \\
\cline { 2 - 8 } & $\mathbf{r}_{\text {AMPS }}$ & $\mathbf{r}_{\text {AAm }}$ & $\mathbf{f}_{\text {AMPS, } \mathbf{0 , 1}}$ & $\mathbf{f}_{\text {AMPS, } \mathbf{0}, \mathbf{2}}$ & $\mathbf{r}_{\text {AMPS }}$ & $\mathbf{r}_{\text {AAm }}$ \\
\hline Preliminary & 0.50 & 1.02 & 0.15 & 0.80 & 0.13 & 0.84 \\
T-M Design & 0.13 & 0.84 & 0.30 & 0.91 & 0.16 & 0.77 \\
EVM Design & 0.13 & 0.84 & 0.10 & 0.84 & 0.18 & 0.85 \\
\hline
\end{tabular}

\subsection{Reactivity Ratio Estimation}

Reactivity ratios are estimated by applying the cumulative composition model (using direct numerical integration) to the data through the error-in-variables-model (EVM). The experimental data are presented in Appendix A (Tables A1 and A2), and details regarding the implementation of this technique have been presented previously by Kazemi et al. [8].

To better appreciate the error associated with each analysis, reactivity ratio point estimates are presented along with their corresponding joint confidence regions (JCRs). JCRs are typically elliptical contours that quantify the level of uncertainty in the parameter estimates; smaller JCRs indicate higher precision and therefore more confidence in the estimation results [7]. The reactivity ratio point estimates for preliminary, T-M-designed and EVM-designed experiments, along with their associated JCRs, are presented in Figure 1. The literature value from McCormick and Chen [26] is also included for comparison purposes.

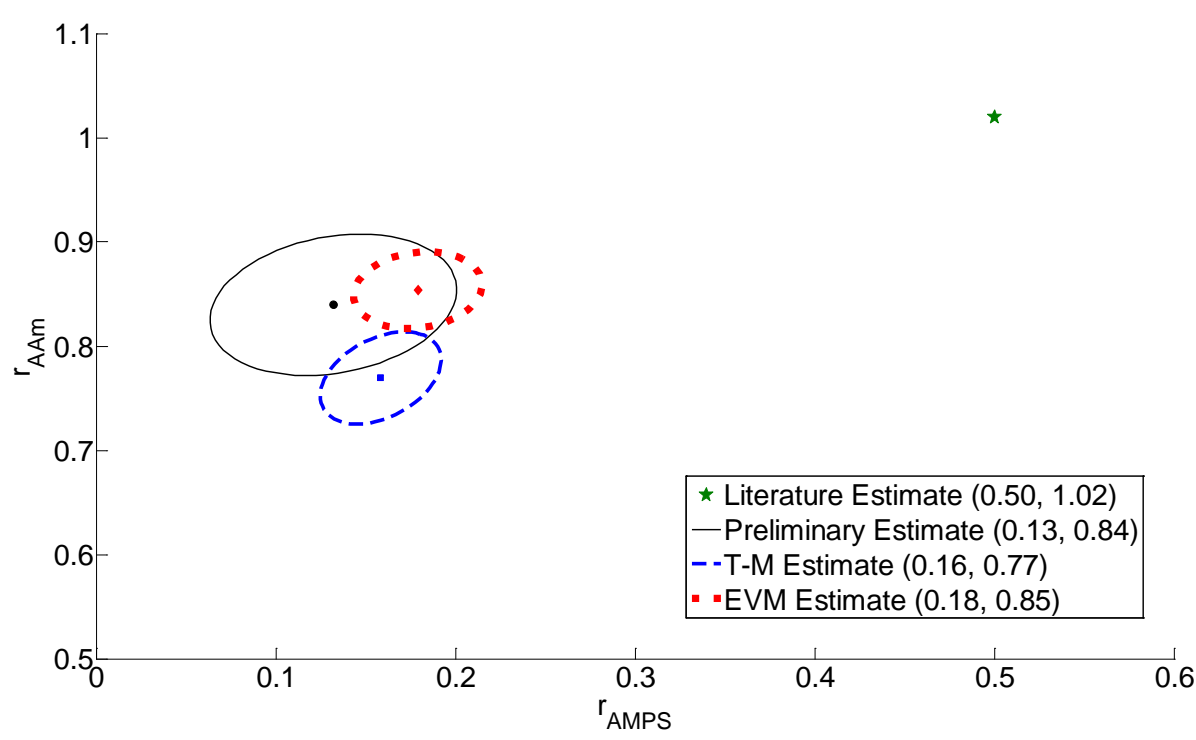

Figure 1. Reactivity ratio estimates for AMPS/AAm copolymer. 
Clearly, the reactivity ratio estimates from McCormick and Chen [26] are different from the newly determined reactivity ratios; the estimates from literature are not contained within any of the JCRs. However, it is important to note that the work by McCormick and Chen [26] was at $\mathrm{pH}=9,30{ }^{\circ} \mathrm{C}$ and used potassium persulfate (KPS) as the initiator. This is in contrast to the current experimental work, which is at $\mathrm{pH}=7,40{ }^{\circ} \mathrm{C}$ and uses ACVA as the initiator. Because the polymerization conditions are different, especially in terms of $\mathrm{pH}$, a difference in results is somewhat expected, although the difference in AMPS values seems considerable.

Overall, all three of the experimental data sets produce similar results. The three JCRs are overlapping, which allows for a high degree of confidence in the results. In comparing the preliminary estimate to the T-M and EVM estimates, the advantages of using optimally designed experiments for reactivity ratio estimation are obvious. The JCRs obtained using the T-M and EVM designs are much smaller than the preliminary design, which indicates that a greater degree of confidence is achieved with the same amount of experimental data.

\subsection{Discussion of Results}

Reactivity ratios are extremely important parameters in copolymerization kinetics. While the point estimates from the T-M and EVM designs were fairly close, it is still important to establish whether differences in reactivity ratio estimates for the same system will affect subsequent calculations. Reactivity ratios can be used to predict polymer properties such as copolymer composition. Since this information could be used for custom polymer production for specific applications [11], the estimates should be as accurate as possible.

\subsubsection{Cumulative Copolymer Composition}

As an example, the initial feed compositions selected using Tidwell-Mortimer designs are examined in Figure 2. Given the reactivity ratios from the two optimal designs and from literature (see Table 2) and the initial feed compositions ( $\mathrm{f}_{\mathrm{AMPS}, 0}=0.30$ and $\mathrm{f}_{\mathrm{AMPS}, 0}=0.91$ ), it is possible to predict the cumulative copolymer composition.

This analysis indicates that slight differences in reactivity ratio estimates can significantly affect the cumulative copolymer composition prediction. When the AMPS content in the feed compositions is low (at $\mathrm{f}_{\mathrm{AMPS}, 0}=0.30$, for example), the model predictions are in very good agreement. In fact, the model predictions for $\mathrm{f}_{\mathrm{AMPS}, 0}=0.30$ from the EVM-design and from McCormick and Chen [26] are almost indistinguishable. However, at $\mathrm{f}_{\mathrm{AMPS}, 0}=0.91$, there is a significant difference in model predictions, especially when comparing the optimally-designed experiments to the literature values. The difference in prediction behavior between $\mathrm{f}_{\mathrm{AMPS}, 0}=0.30$ and $\mathrm{f}_{\mathrm{AMPS}, 0}=0.91$ is due to the nature of the system. When the AMPS content is low in the feed, there is very little composition drift (that is, $\mathrm{f}_{\text {AMPS }} \approx \mathrm{F}_{\text {AMPS }}$ ), which means that the reactivity ratios do not have a significant influence on the copolymer composition predictions. Conversely, when $\mathrm{f}_{\mathrm{AMPS}, 0}$ is high, the propagation of error is evident in the model predictions. Again, this highlights the importance of obtaining accurate reactivity ratios in order to calculate other copolymer property trajectories properly. 


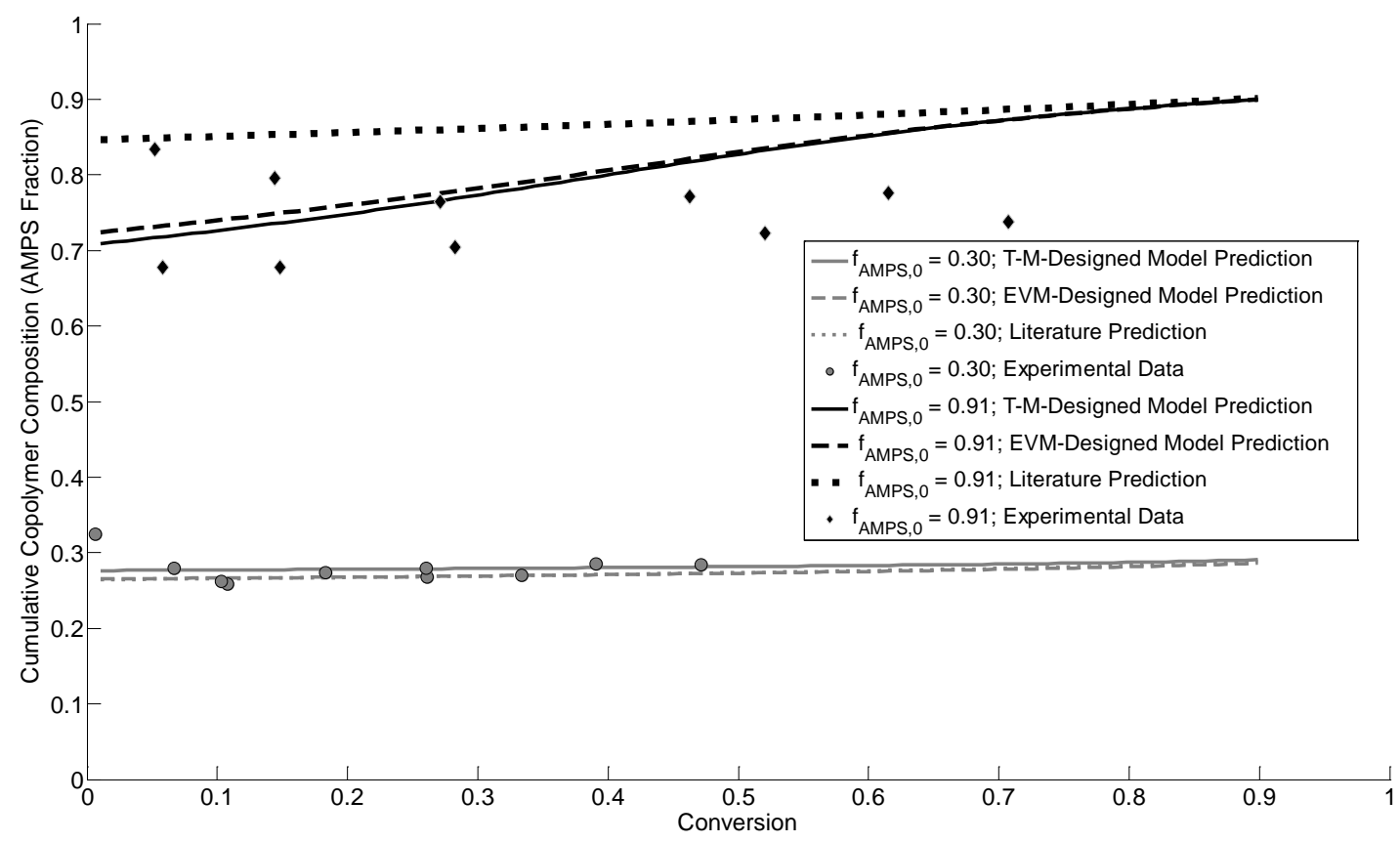

Figure 2. Cumulative copolymer composition for AMPS/AAm; T-M-designed experiments $\left(\mathrm{f}_{\mathrm{AMPS}, 0}=0.30\right.$ and $\left.\mathrm{f}_{\mathrm{AMPS}, 0}=0.91\right)$.

\subsubsection{Instantaneous Copolymer Composition}

The instantaneous copolymer composition can be predicted in the same way that the cumulative copolymer composition was established (using feed compositions and reactivity ratio estimates). As an example, the cumulative and instantaneous composition predictions for $\mathrm{f}_{\mathrm{AMPS}, 0}=0.84$ are presented in Figure 3.

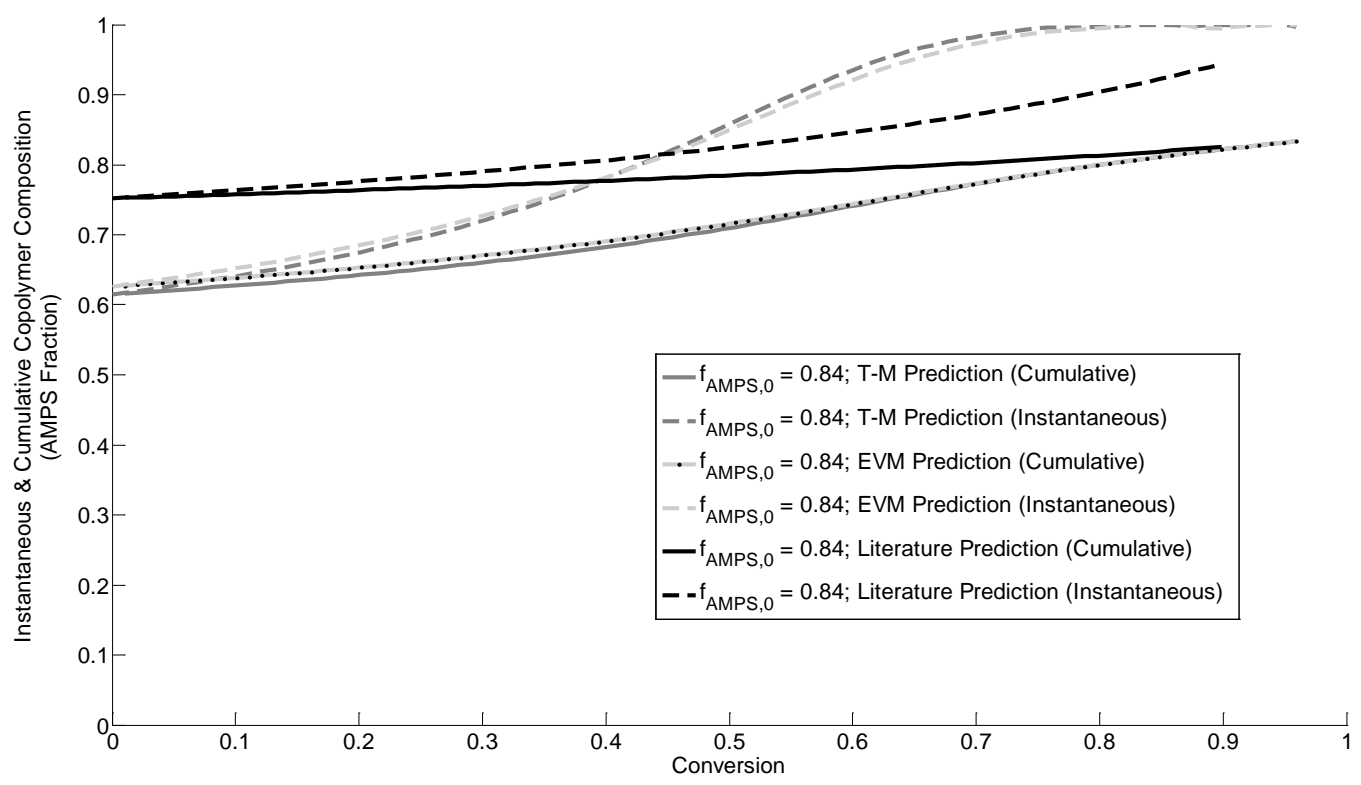

Figure 3. Instantaneous and cumulative copolymer composition predictions (AMPS/AAm).

Figure 3 shows clear similarities between the T-M-designed prediction and the EVM-designed prediction, with slight discrepancies at low conversion. However, the trends are consistent, and the two 
models seem to converge at higher levels of conversion (>50\%). Conversely, the instantaneous and cumulative copolymer composition models using the reactivity ratios from McCormick and Chen [26] give very different results. The initial copolymer composition is at least $10 \%$ higher than that predicted by the current investigation, and the trends differ significantly. This is another indication that the reliability of reactivity ratios is extremely important (especially when $\mathrm{f}_{\mathrm{AMPS}, 0}$ is high), which confirms previous observations.

\subsubsection{Azeotrope Analysis}

As mentioned previously, reactivity ratios can be used to estimate the azeotropic composition for a copolymer. Equation (4) can be used to establish azeotropic composition, or $\mathrm{F}_{\text {AMPS }}$ can be plotted as a function of $\mathrm{f}_{\mathrm{AMPS}}$ to establish the azeotropic point.

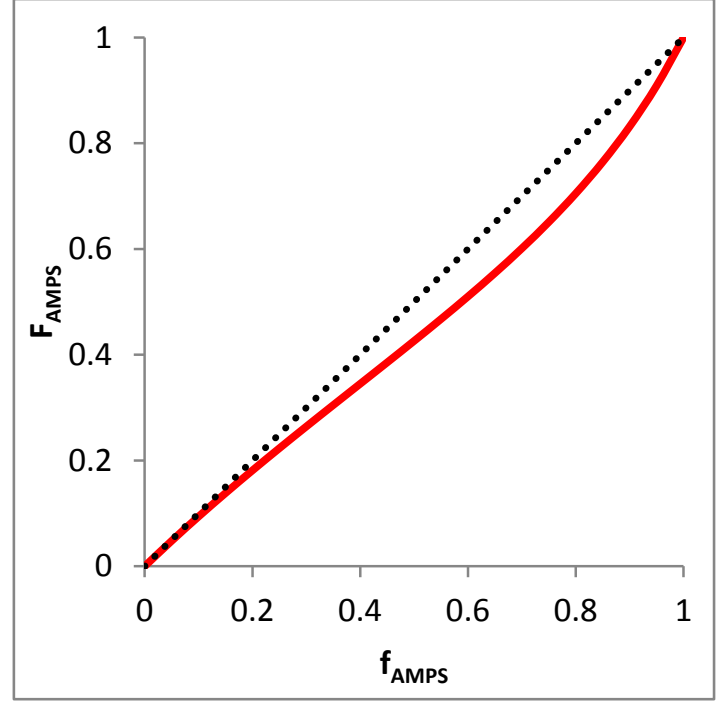

(a)

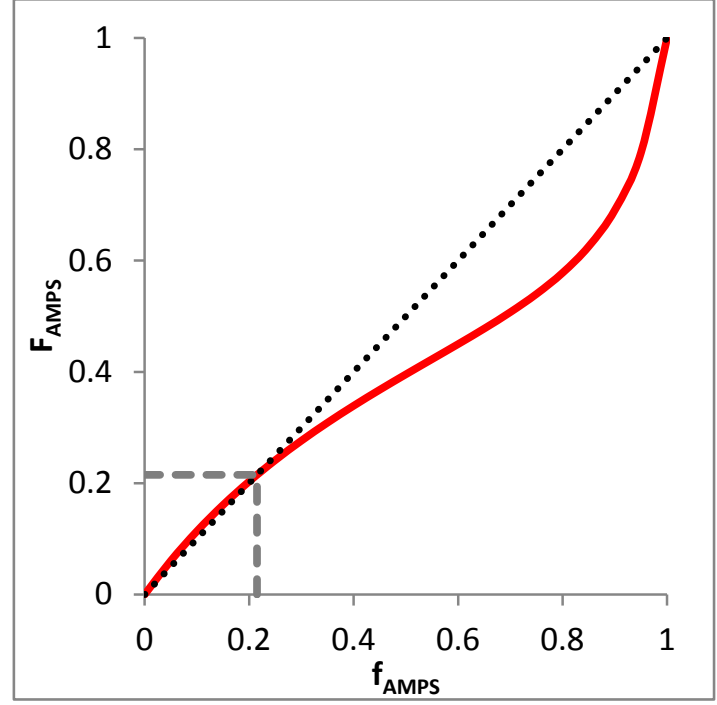

(c)

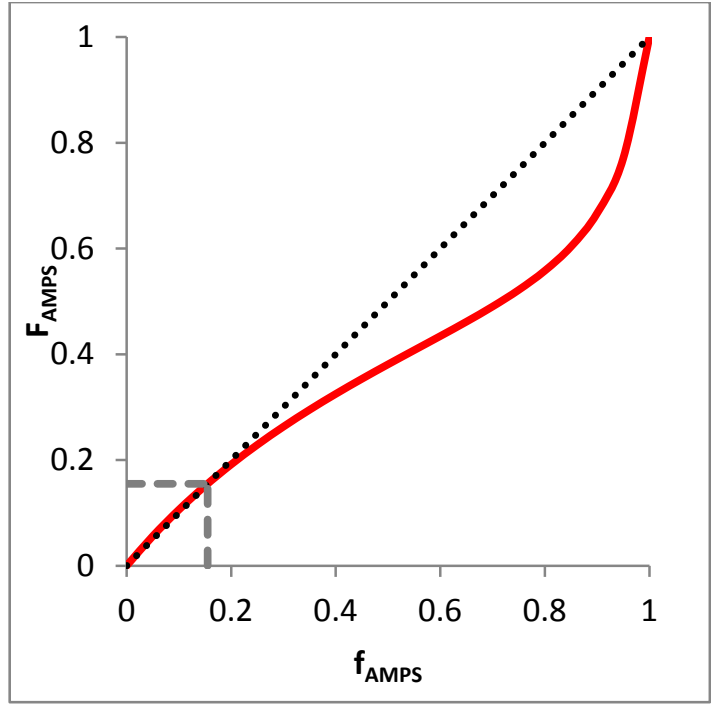

(b)

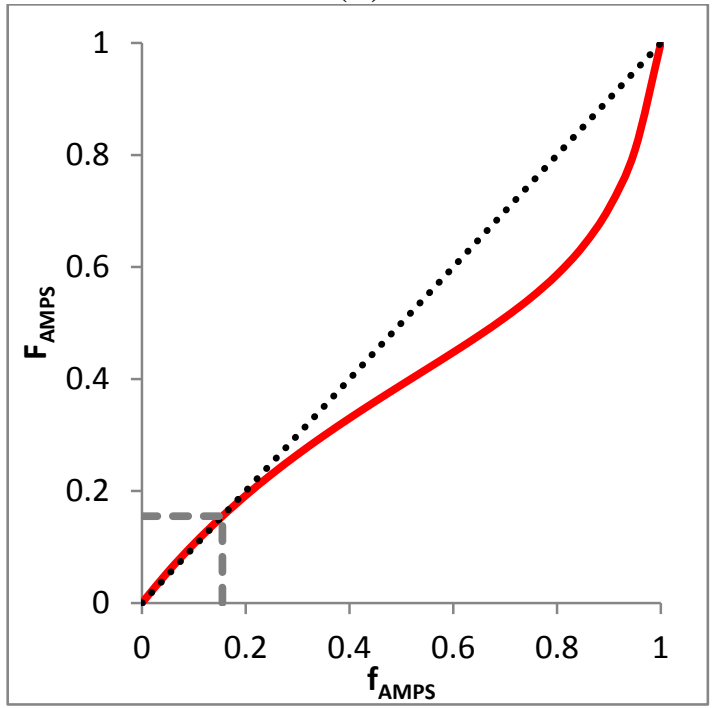

(d)

Figure 4. Determination of azeotropic composition from (a) literature data [26]; (b) preliminary data; (c) T-M-designed data; and (d) EVM-designed data; $45^{\circ}$ line $\left(\mathrm{F}_{\mathrm{AMPS}}=\mathrm{f}_{\mathrm{AMPS}}\right)$ indicated by a dotted line. 
Figure 4 demonstrates how $F_{\text {AMPS }}$ varies with $\mathrm{f}_{\text {AMPS }}$, given four sets of reactivity ratio estimates ((a) literature data; (b) preliminary data; (c) T-M-designed data; and (d) EVM-designed data). The point at which the curve passes through the $45^{\circ}$ line $\left(\mathrm{F}_{\mathrm{AMPS}}=\mathrm{f}_{\mathrm{AMPS}}\right.$, here indicated by a dotted line) represents the azeotropic composition.

It is important to note that $\mathrm{f}_{\mathrm{AMPS}} \approx \mathrm{F}_{\text {AMPS }}$ (that is, the $\mathrm{F}_{\text {AMPS }}$ curve falls very close to the $45^{\circ}$ line) at low values of $f_{A M P S}$ in all cases, which confirms the results of Figure 2. However, as expected, the curve never passes through the $45^{\circ}$ line in case (a). From a mathematical perspective, it is only feasible to observe a non-negative azeotropic point in the binary system when both reactivity ratios are less than or greater than unity; according to McCormick and Chen [26], $\mathrm{r}_{\mathrm{AMPS}}=0.50$ and $\mathrm{r}_{\mathrm{AAm}}=1.02$. Therefore, their reactivity ratio estimates suggest that an azeotrope does not occur in this system.

However, in cases (b) through (d), both reactivity ratios are less than unity. Therefore, we expect to observe an azeotrope in the system, and the plots confirm these expectations. Using the reactivity ratios found with T-M-designed data (case (c); $\mathrm{r}_{\mathrm{AMPS}}=0.16$ and $\mathrm{r}_{\mathrm{AAm}}=0.77$ ), the azeotrope occurs at $\mathrm{f}_{\mathrm{AMPS}}=\mathrm{F}_{\mathrm{AMPS}}=0.22$. On the other hand, reactivity ratios from the preliminary (case (b); $\mathrm{r}_{\mathrm{AMPS}}=0.13$ and $\left.\mathrm{r}_{\mathrm{AAm}}=0.84\right)$ and the EVM-designed data (case $(\mathrm{d}) ; \mathrm{r}_{\mathrm{AMPS}}=0.18$ and $\mathrm{r}_{\mathrm{AAm}}=0.85$ ) both predict the azeotropic composition to be $\mathrm{f}_{\mathrm{AMPS}}=\mathrm{F}_{\mathrm{AMPS}}=0.16$. Hence, the location of the system azeotrope is somewhere between 0.16 and 0.22 .

The agreement between the preliminary and EVM-designed results, combined with the small JCR and high degree of confidence associated with the EVM-designed experiments (even with a limited number of data points, as is evident from Appendix A), give reason to believe that the reactivity ratios obtained through EVM-designed experiments are more trustworthy overall. Therefore, for the AMPS/AAm copolymer system, $\mathrm{r}_{\mathrm{AMPS}}=0.18$ and $\mathrm{r}_{\mathrm{AAm}}=0.85$.

\section{AMPS/AAc Copolymer}

\subsection{Literature Background for AMPS/AAc}

Very few studies have been found with regards to the copolymerization of 2-acrylamido-2methylpropane sulfonic acid (AMPS) and acrylic acid (AAc). Even fewer have investigated the polymerization kinetics and, specifically, copolymer reactivity ratios. In previous studies, AMPS and AAc have been copolymerized in the presence of crosslinking agents [28-30], and the crosslinked products have been grafted onto backbones via free radical graft polymerization [31,32] to produce hydrogels.

Table 3. Reactivity ratio estimates for AMPS/AAc copolymer.

\begin{tabular}{lllcc}
\hline Ref. & \multicolumn{1}{c}{ Experimental } & Estimation Technique & $\mathbf{r}_{\text {AMPS }}$ & $\mathbf{r}_{\text {AAc }}$ \\
\hline & --Type: Aqueous solution & & & \\
& copolymerization $(<10 \%$ conversion) & Fineman-Ross & 0.304 & 0.915 \\
{$[28]$} & --Initiator: BPO & Kelen-Tudos & 0.15 & 0.98 \\
& --Temperature: $55^{\circ} \mathrm{C}$ & Average & 0.27 & 0.95 \\
& --Composition: IR & & & \\
\hline & --Type: Aqueous solution & 0.194 & 0.700 \\
{$[33]$} & copolymerization $(<10 \%$ conversion) & Fineman-Ross & $0.187 \pm 0.09$ & $0.740 \pm 0.13$ \\
& --pH $=7$ & Behnken's NLR & & \\
\hline
\end{tabular}

Nomenclature: AAc, acrylic acid; AMPS, 2-acrylamido-2-methylpropane sulfonic acid; BPO, benzoyl peroxide; EA, elemental analysis; IR, infrared spectroscopy; NLR, non-linear regression. 
Only two studies [28,33] have been identified that provided reactivity ratio estimates for the AMPS/AAc copolymer along with a description of synthesis and characterization methods (see Table 3). In the work by Abdel-Azim et al. [28], reactivity ratios for the AMPS/AAc copolymer were estimated using the Fineman-Ross and Kelen-Tudos (linear) methods. The authors chose to average the two values obtained by the two techniques, which can be a gross approximation for $\mathrm{r}_{\text {AMPS. }}$.

\subsection{Design of Experiments for AMPS/AAc}

Preliminary experiments for AMPS/AAc were based on literature values from Abdel-Azim et al. [28]. Both preliminary feed compositions $\left(\mathrm{f}_{\mathrm{AMPS}, 0}=0.15\right.$ and $\mathrm{f}_{\mathrm{AMPS}, 0}=0.80$ ) presented unique concerns (see Table 4). At the lower AMPS feed composition $\left(\mathrm{f}_{\mathrm{AMPS}, 0}=0.15\right.$ ), the copolymerization was extremely slow and minimal precipitate formed. The high AMPS run $\left(\mathrm{f}_{\mathrm{AMPS}, 0}=0.80\right.$ ) was better in terms of conversion and copolymer precipitation, but presented other difficulties. The reaction took place very quickly, which significantly increased variability in the system. This is, to some extent, characteristic of preliminary experiments, and the error observed in the replicates decreased substantially for the optimally designed experiments.

Table 4. Design of experiments and reactivity ratio estimates for AMPS/AAc.

\begin{tabular}{ccccccc}
\hline \multirow{2}{*}{ Approach } & \multicolumn{2}{c}{ Reactivity Ratios for Design } & \multicolumn{2}{c}{ Feed Compositions (Mole Fractions) } & \multicolumn{2}{c}{ New Reactivity Ratio Estimates } \\
\cline { 2 - 7 } & $\mathbf{r}_{\text {AMPS }}$ & $\mathbf{r}_{\text {AAc }}$ & $\mathbf{f}_{\text {AMPS, } \mathbf{0 , 1}}$ & $\mathbf{f}_{\text {AMPS, }, \mathbf{2}}$ & $\mathbf{r}_{\text {AMPS }}$ & $\mathbf{r}_{\text {AAc }}$ \\
\hline Preliminary & 0.27 & 0.95 & 0.15 & 0.80 & 0.48 & 0.95 \\
T-M Design & 0.48 & 0.95 & 0.32 & 0.81 & 0.21 & 0.85 \\
EVM Design & 0.48 & 0.95 & 0.20 & 0.73 & 0.19 & 0.86 \\
\hline
\end{tabular}

Fortunately, one of the advantages associated with EVM is the ability to introduce constraints on the experimental design. To avoid the excessively slow polymerization and poor precipitation that was observed for $\mathrm{f}_{\mathrm{AMPS}, 0}=0.15$, a constraint $\left(0.2<\mathrm{f}_{\mathrm{AMPS}, 0}<1.0\right)$ was included when designing optimal experiments through EVM.

\subsection{Reactivity Ratio Estimation}

Reactivity ratios were calculated using conversion and cumulative composition data (see Appendix A, Tables A3 and A4). The cumulative composition model was applied to the data (using direct numerical integration as described in Kazemi et al. [8]) through EVM. Point estimates from the literature [28], the preliminary experiments and the optimally designed experiments are presented in Figure 5, along with their corresponding JCRs. 


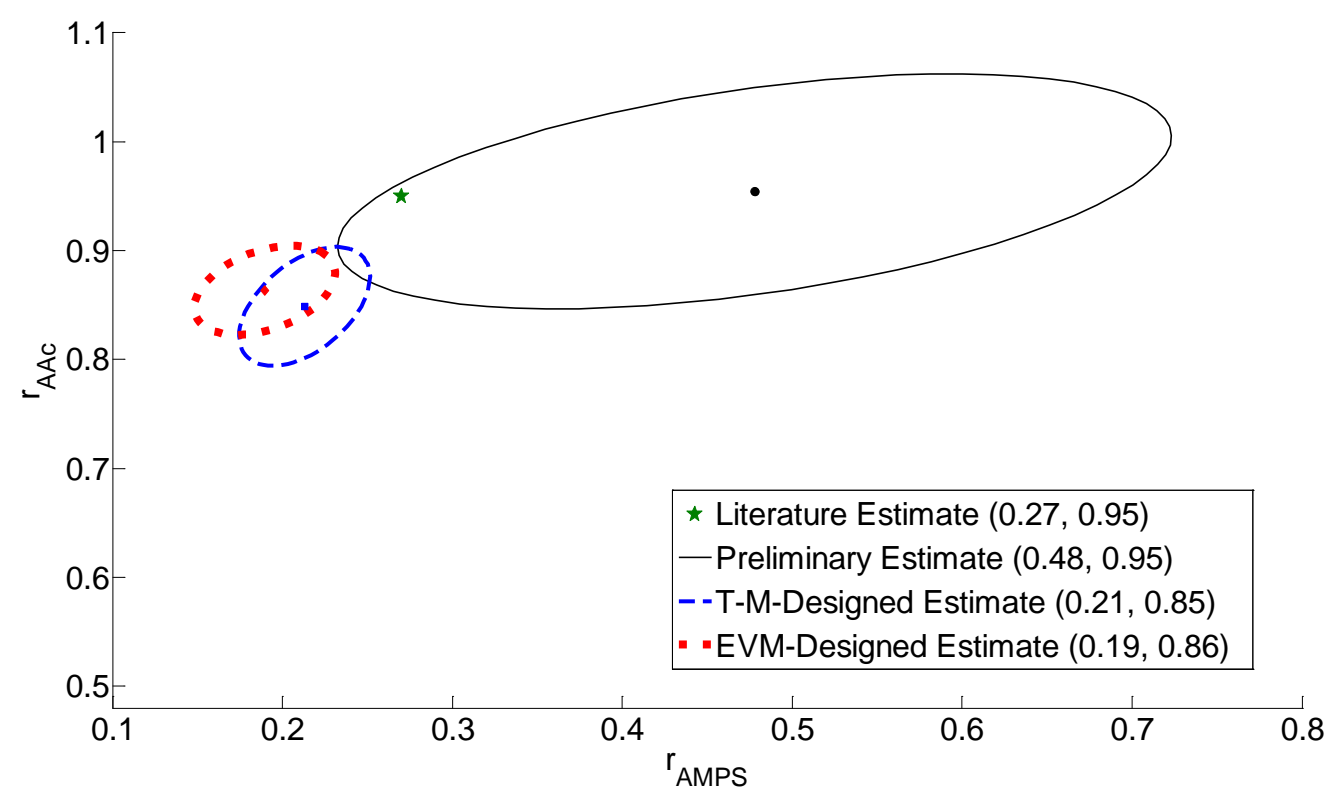

Figure 5. Reactivity ratio estimates for AMPS/AAc copolymer.

The point estimate from Abdel-Azim et al. [28] is very close to the edge of the preliminary JCR. While it is reassuring to see that the literature estimates are contained within the preliminary JCR, the preliminary JCR is quite large (as is usually expected for preliminary experimental work). The study by Abdel-Azim et al. [28] provided limited insight as to the polymerization conditions for the synthesis of the AMPS/AAc copolymer, but the initiator (benzoyl peroxide) and reaction temperature $\left(55^{\circ} \mathrm{C}\right.$ ) differed from the currently used conditions. Arguably one of the most important reaction conditions, $\mathrm{pH}$, is not mentioned at all in the work by Abdel-Azim et al. [28], so a direct comparison is difficult. However, in general, the estimates made in the previous literature study seem to be close to our newly determined reactivity ratios.

As expected, using experiments that were designed using the Tidwell-Mortimer technique and the error-in-variables-model significantly decreased the error associated with the reactivity ratio estimates. The optimally designed estimates are in relatively good agreement with both the preliminary estimates and the literature values, which allows for a high degree of confidence in the results. The significant overlap between JCRs from the T-M-designed and EVM-designed experiments is also a very good sign, and provides additional confidence in these results.

\subsection{Discussion of Results}

Because the reactivity ratio estimates from literature, T-M design and EVM design are all similar, it is unlikely that the differences in values will affect composition predictions or other calculations related to copolymer microstructure. However, it is still useful to compare model predictions to experimental results as a confirmation step.

It is reasonable to assume that the EVM-designed results are more accurate, as they were for the AMPS/AAm copolymer (see again Figure 1). However, since the JCRs are close in size (given a similar number of data points in each analysis), it is also helpful to quantify the difference between the two designs. Therefore, the following ratio can be used to compare the confidence regions of the parameters [34]: 


$$
\frac{\text { Volume }_{\mathrm{T}-\mathrm{M} \text { Design }}}{\text { Volume }_{\mathrm{EVM} \text { Design }}} \propto\left(\frac{\left|\mathrm{G}_{\mathrm{EVM} \text { Design }}\right|}{\left|\mathrm{G}_{\mathrm{T}-\mathrm{M} \text { Design }}\right|}\right)^{\frac{1}{2}}
$$

where $\left|\mathrm{G}_{\mathrm{i}}\right|$ is the determinant of the EVM (or T-M) design criterion for a given design of experiments. For the data of Figure 5, the JCR volume ratio is 1.1659, which indicates that the JCR from the T-M design is larger than the JCR from the EVM design [34]. The detailed calculation is provided in Appendix A, Section A.3; the analysis confirms that the EVM-designed experiments produce the smallest JCR for the AMPS/AAc copolymer. An additional advantage of the EVM-designed experiments, which is observed in both Figure 1 and Figure 5, is the decrease in correlation between reactivity ratios compared to the T-M-designed results (as indicated by the decreased slope of the error ellipse). Therefore, the EVM-designed reactivity ratios $\mathrm{r}_{\mathrm{AMPS}}=0.19$ and $\mathrm{r}_{\mathrm{AAm}}=0.86$ can be used to calculate cumulative copolymer composition profiles. Results are shown in Figure 6.

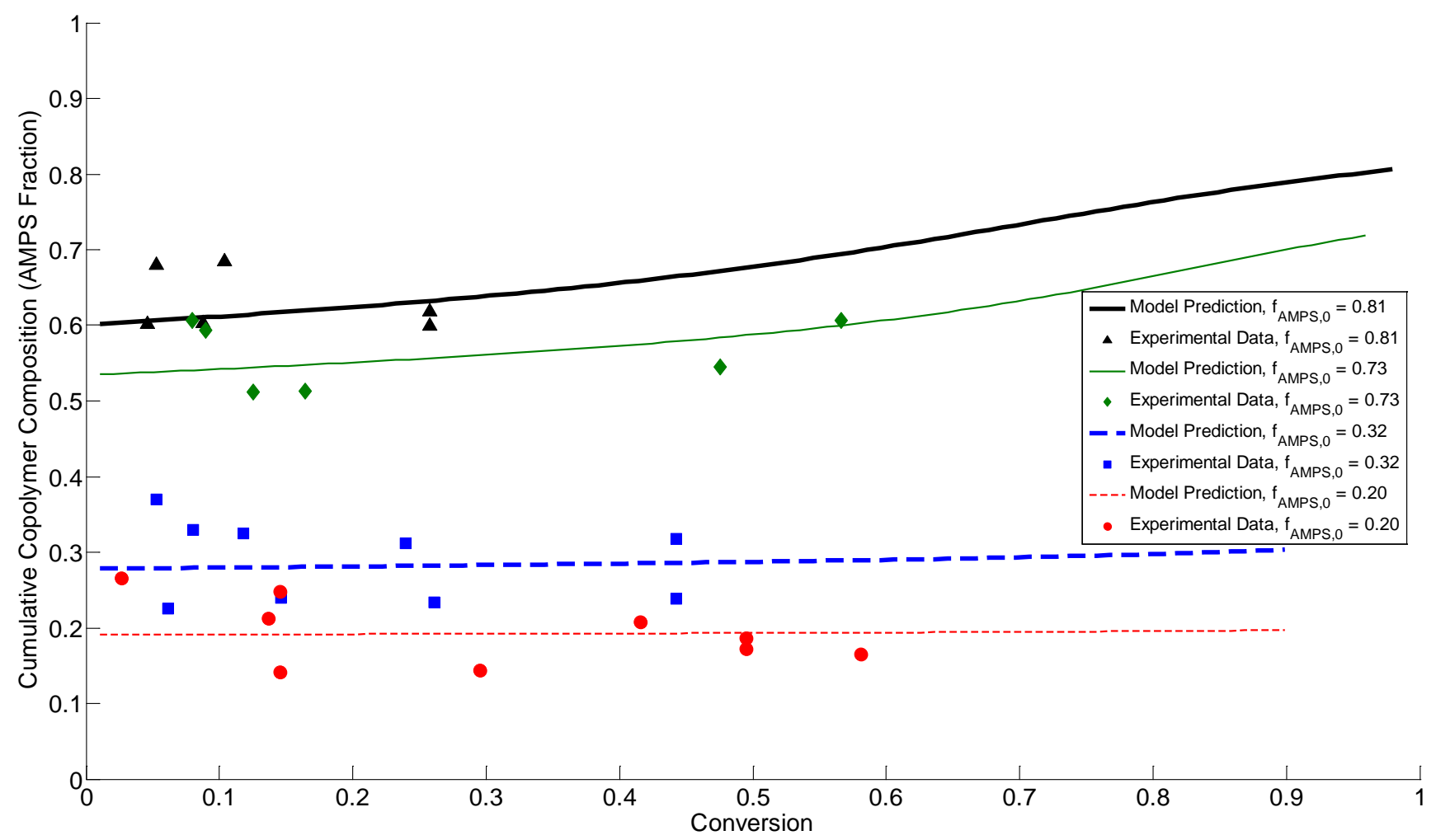

Figure 6. Cumulative copolymer composition for AMPS/AAc.

Here, we see good agreement between the model predictions and the experimental results. Due to the high confidence in reactivity ratio estimates (based on the size of the JCRs and other reasons described earlier), any discrepancies between the data and the model are likely due to errors inherent in the experimental measurements. 


\section{Conclusions}

To improve the shear strength of the AAm/AAc copolymer, often used in enhanced oil recovery, it may be beneficial to add AMPS to the pre-polymerization mixture. To learn more about the AMPS/AAm/AAc terpolymer, reactivity ratios for two associated copolymerizations, AMPS/AAm and AMPS/AAc were established. These binary reactivity ratios can be used with a higher level of confidence (compared to prior literature sources), as many sources of error associated with previous estimation techniques have been removed. The results are summarized in Table 5.

Table 5. Summary of reactivity ratio estimates.

\begin{tabular}{ccc}
\hline Copolymer & $\mathbf{r}_{\mathbf{1}}$ & $\mathbf{r}_{\mathbf{2}}$ \\
\hline $\mathrm{AMPS}^{1} / \mathrm{AAm}^{2}$ & 0.18 & 0.85 \\
$\mathrm{AMPS}^{1} / \mathrm{AAc}^{2}$ & 0.19 & 0.86 \\
\hline
\end{tabular}

The copolymerization experiments (AMPS/AAm and AMPS/AAc) were designed using two optimal techniques: Tidwell-Mortimer and the error-in-variables-model (EVM). The best estimates (that is, those with the highest degree of confidence) were those obtained from the EVM-designed data, but both techniques gave similar results. All optimally-designed experiments led to smaller joint confidence regions (JCRs), which is indicative of greater confidence in the reactivity ratio estimates.

\section{Acknowledgments}

The authors wish to acknowledge financial support from the Natural Sciences and Engineering Research Council (NSERC) of Canada, and the Canada Research Chair (CRC) program. Thanks also go to UWW/OMNOVA Solutions, USA, for special support to A.J.S.

\section{Author Contributions}

This paper is based on the MASc thesis by Alison J. Scott, which was an offspring of the PhD thesis by Marzieh Riahinezhad. Alexander Penlidis supervised both theses.

\section{Conflicts of Interest}

The authors declare no conflict of interest. 


\section{Appendix A: Experimental Data}

\section{A.1. AMPS/AAm Copolymerization Data}

Table A1. Experimental data for AMPS/AAm copolymerization; Tidwell-Mortimer design.

\begin{tabular}{|c|c|c|c|c|c|}
\hline Run \# & $\mathbf{X}$ & $\mathbf{f}_{\text {AMPS }, 0}$ & $\mathbf{f}_{\mathrm{AAm}, 0}$ & $\overline{\mathbf{F}}_{\text {AMPS }}$ & $\overline{\mathbf{F}}_{\mathrm{AAm}}$ \\
\hline \multirow{5}{*}{1} & 0.0061 & 0.30 & 0.70 & 0.3243 & 0.6757 \\
\hline & 0.1078 & 0.30 & 0.70 & 0.2592 & 0.7408 \\
\hline & 0.2614 & 0.30 & 0.70 & 0.2683 & 0.7317 \\
\hline & 0.3335 & 0.30 & 0.70 & 0.2701 & 0.7299 \\
\hline & 0.4717 & 0.30 & 0.70 & 0.2841 & 0.7159 \\
\hline \multirow{5}{*}{2} & 0.0583 & 0.91 & 0.09 & 0.6772 & 0.3228 \\
\hline & 0.1483 & 0.91 & 0.09 & 0.6779 & 0.3221 \\
\hline & 0.2829 & 0.91 & 0.09 & 0.7043 & 0.2957 \\
\hline & 0.5207 & 0.91 & 0.09 & 0.7223 & 0.2777 \\
\hline & 0.7076 & 0.91 & 0.09 & 0.7374 & 0.2626 \\
\hline \multirow{5}{*}{3} & 0.0671 & 0.30 & 0.70 & 0.2794 & 0.7206 \\
\hline & 0.1035 & 0.30 & 0.70 & 0.2626 & 0.7374 \\
\hline & 0.1830 & 0.30 & 0.70 & 0.2735 & 0.7265 \\
\hline & 0.2604 & 0.30 & 0.70 & 0.2797 & 0.7203 \\
\hline & 0.3910 & 0.30 & 0.70 & 0.2858 & 0.7142 \\
\hline \multirow{5}{*}{4} & 0.0519 & 0.91 & 0.09 & 0.8335 & 0.1665 \\
\hline & 0.1441 & 0.91 & 0.09 & 0.7955 & 0.2045 \\
\hline & 0.2710 & 0.91 & 0.09 & 0.7648 & 0.2352 \\
\hline & 0.4626 & 0.91 & 0.09 & 0.7715 & 0.2285 \\
\hline & 0.6151 & 0.91 & 0.09 & 0.7762 & 0.2238 \\
\hline
\end{tabular}

$\mathrm{X}=$ conversion; $\mathrm{f}_{\mathrm{AMPS}, 0}=$ mole fraction of AMPS in the initial monomer feed; $\overline{\mathrm{F}}_{\mathrm{AMPS}}=$ cumulative mole fraction (composition) of AMPS in the copolymer product. These symbols are used throughout this Appendix.

Table A2. Experimental data for AMPS/AAm copolymerization; Error-in-Variables-Model design.

\begin{tabular}{cccccc}
\hline Run \# & $\mathbf{X}$ & $\mathbf{f}_{\text {AMPS, } \mathbf{0}}$ & $\mathbf{f}_{\text {AAm }, \mathbf{0}}$ & $\overline{\mathbf{F}}_{\text {AMPS }}$ & $\overline{\mathbf{F}}_{\text {AAm }}$ \\
\hline \multirow{3}{*}{1} & 0.3408 & 0.10 & 0.90 & 0.1141 & 0.8859 \\
& 0.3425 & 0.10 & 0.90 & 0.0937 & 0.9063 \\
& 0.7073 & 0.10 & 0.90 & 0.0801 & 0.9199 \\
\hline \multirow{3}{*}{2} & 0.0731 & 0.84 & 0.16 & 0.5977 & 0.4023 \\
& 0.1412 & 0.84 & 0.16 & 0.6332 & 0.3668 \\
& 0.1923 & 0.84 & 0.16 & 0.7141 & 0.2859 \\
& 0.3348 & 0.84 & 0.16 & 0.6555 & 0.3445 \\
\hline \multirow{3}{*}{3} & 0.1064 & 0.10 & 0.90 & 0.1681 & 0.8319 \\
& 0.1473 & 0.10 & 0.90 & 0.0911 & 0.9089 \\
& 0.3556 & 0.10 & 0.90 & 0.0898 & 0.9102 \\
\multirow{2}{*}{4} & 0.6174 & 0.10 & 0.90 & 0.0922 & 0.9078 \\
\hline & 0.2862 & 0.84 & 0.16 & 0.7030 & 0.2970 \\
& 0.3589 & 0.84 & 0.16 & 0.6938 & 0.3062 \\
\hline
\end{tabular}




\section{A.2. AMPS/AAc Copolymerization Data}

Table A3. Experimental data for AMPS/AAc copolymerization; Tidwell-Mortimer design.

\begin{tabular}{cccccc}
\hline Run \# & $\mathbf{X}$ & $\mathbf{f}_{\text {AMPS, } \mathbf{0}}$ & $\mathbf{f}_{\text {AAc, } \mathbf{0}}$ & $\overline{\mathbf{F}}_{\text {AMPS }}$ & $\overline{\mathbf{F}}_{\text {AAc }}$ \\
\hline \multirow{4}{*}{1} & 0.0617 & 0.32 & 0.68 & 0.2259 & 0.7741 \\
& 0.1461 & 0.32 & 0.68 & 0.2397 & 0.7603 \\
& 0.2613 & 0.32 & 0.68 & 0.2333 & 0.7667 \\
& 0.4426 & 0.32 & 0.68 & 0.2386 & 0.7614 \\
& 0.4426 & 0.32 & 0.68 & 0.3182 & 0.6818 \\
\hline \multirow{2}{*}{2} & 0.0462 & 0.81 & 0.19 & 0.6014 & 0.3986 \\
& 0.0874 & 0.81 & 0.19 & 0.6032 & 0.3968 \\
\hline \multirow{3}{*}{3} & 0.0528 & 0.32 & 0.68 & 0.3701 & 0.6299 \\
& 0.0804 & 0.32 & 0.68 & 0.3298 & 0.6702 \\
& 0.1177 & 0.32 & 0.68 & 0.3253 & 0.6747 \\
& 0.2395 & 0.32 & 0.68 & 0.3120 & 0.6880 \\
\hline \multirow{4}{*}{4} & 0.0524 & 0.81 & 0.19 & 0.6802 & 0.3198 \\
& 0.1038 & 0.81 & 0.19 & 0.6849 & 0.3151 \\
& 0.2576 & 0.81 & 0.19 & 0.6182 & 0.3818 \\
& 0.2576 & 0.81 & 0.19 & 0.5992 & 0.4008 \\
\hline
\end{tabular}

Table A4. Experimental data for AMPS/AAc copolymerization; Error-in-Variables-Model design.

\begin{tabular}{cccccc}
\hline Run \# & $\mathbf{X}$ & $\mathbf{f}_{\text {AMPS, } \mathbf{0}}$ & $\mathbf{f}_{\text {AAc, } \mathbf{0}}$ & $\overline{\mathbf{F}}_{\text {AMPS }}$ & $\overline{\mathbf{F}}_{\text {AAc }}$ \\
\hline \multirow{6}{*}{1} & 0.0269 & 0.20 & 0.80 & 0.2652 & 0.7348 \\
& 0.1369 & 0.20 & 0.80 & 0.2119 & 0.7881 \\
& 0.4156 & 0.20 & 0.80 & 0.2075 & 0.7925 \\
& 0.4950 & 0.20 & 0.80 & 0.1860 & 0.8140 \\
& 0.4950 & 0.20 & 0.80 & 0.1723 & 0.8277 \\
& 0.5813 & 0.20 & 0.80 & 0.1649 & 0.8351 \\
\hline \multirow{3}{*}{2} & 0.0895 & 0.73 & 0.27 & 0.5939 & 0.4061 \\
& 0.1250 & 0.73 & 0.27 & 0.5115 & 0.4885 \\
& 0.1642 & 0.73 & 0.27 & 0.5131 & 0.4869 \\
\hline \multirow{3}{*}{3} & 0.1458 & 0.20 & 0.80 & 0.2474 & 0.7526 \\
& 0.1458 & 0.20 & 0.80 & 0.1418 & 0.8582 \\
& 0.2951 & 0.20 & 0.80 & 0.1439 & 0.8561 \\
\hline \multirow{4}{*}{4} & 0.0798 & 0.73 & 0.27 & 0.6063 & 0.3937 \\
& 0.4756 & 0.73 & 0.27 & 0.5455 & 0.4545 \\
& 0.5664 & 0.73 & 0.27 & 0.6069 & 0.3931 \\
\hline
\end{tabular}

\section{A.3. Design and Joint Confidence Region Comparison Calculations for AMPS/AAc}

A common discussion in the field of model-based design of experiments (DOEs) is the need to have a criterion of optimality or efficiency through which designs can be ranked. One comparison metric, the determinant of the information matrix, is related to the volume of the JCR and can therefore determine quantitatively which DOE method is superior. In order to compare two design criteria, a ratio between volumes (obtained from different DOE techniques) is frequently used in the literature [34]. 
This ratio offers a direct comparison between the sizes of the confidence regions associated with the parameter estimates. Since a more precise parameter estimate (smaller JCR) is indicative of a better and more efficient design, the criterion depends on whether or not the following ratio is greater or less than unity. As shown previously in Equation (6):

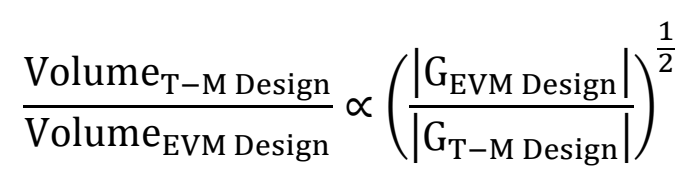

where $\left|G_{i}\right|$ is the determinant of the EVM (or T-M) design criterion for a given design of experiments. If the ratio is less than unity, the EVM-designed data has a larger JCR, and the T-M design is superior. Similarly, if the ratio is greater than unity, the T-M-designed data has a larger JCR, and the EVM design is more efficient. The information used for the analysis of AMPS/AAc in Section 4.4 is provided in Table A5, below:

Table A5. Comparison of design criteria for AMPS/AAc copolymerization.

\begin{tabular}{cc}
\hline T-M-Designed Data: & EVM-Designed Data: \\
\hline $\mathrm{G}=\left[\begin{array}{cc}5369.3 & -1869.2 \\
-1869.2 & 2661.0\end{array}\right]$ & $\mathrm{G}=\left[\begin{array}{cc}4100.6 & -1608.0 \\
-1608.0 & 4208.8\end{array}\right]$ \\
$\left|\mathrm{G}_{\mathrm{T}-\mathrm{M} \text { Design }}\right|=1.0794 \times 10^{7}$ & $\left|\mathrm{G}_{\text {EVM Design }}\right|=1.4673 \times 10^{7}$ \\
\hline
\end{tabular}

$$
\frac{\text { Volume }_{\text {T-M Design }}}{\text { Volume }_{\text {EVM Design }}} \propto\left(\frac{\left|G_{\text {EVM Design }}\right|}{\left|G_{\text {T-M Design }}\right|}\right)^{\frac{1}{2}}=\left(\frac{1.4673 \times 10^{7}}{1.0794 \times 10^{7}}\right)^{\frac{1}{2}}=1.1659
$$

Since the ratio is greater than unity, the JCR from the T-M design is larger than the JCR from the EVM design [34]. Therefore, the EVM-designed information is more accurate.

\section{References}

1. Zaitoun, A.; Makakou, P.; Blin, N.; Al-Maamari, R.; Al-Hashmi, A.; Abdel-Goad, M.; Al-Sharji, H. Shear stability of EOR polymers. In Society of Petroleum Engineers International Symposium; Society of Petroleum Engineers: The Woodlands, TX, USA, 2011.

2. Li, Q.; Pu, W.; Wang, Y.; Zhao, T. Synthesis and assessment of a novel AM-co-AMPS polymer for enhanced oil recovery (EOR). In Proceedings of the Fifth International Conference on Computational and Information Sciences, Shiyan, Hubei, China, 21-23 June 2013.

3. Kamal, M.S.; Sultan, A.S.; Al-Mubaiyedh, U.A.; Hussien, I.A.; Pabon, M. Evaluation of rheological and thermal properties of a new fluorocarbon surfactant-polymer system for EOR applications in high-temperature and high-salinity oil reservoirs. J. Surfactants Deterg. 2014, 17, 985-993.

4. Seright, R.S.; Campbell, A.R.; Mozley, P.S.; Han, P. Stability of partially hydrolyzed polyacrylamides at elevated temperatures in the absence of divalent cations. SPE J. 2010, 15, 341-348.

5. Riahinezhad, M.; Kazemi, N.; McManus, N.; Penlidis, A. Optimal estimation of reactivity ratios for acrylamide/acrylic acid. J. Polym. Sci. Part A Polym. Chem. 2013, 51, 4819-4827. 
6. Reilly, P.M.; Reilly, H.V.; Keeler, S.E. Parameter estimation in the error-in-variables model. J. Royal Stat. Soc. Ser. C Appl. Stat. 1993, 42, 693-701.

7. Kazemi, N.; Duever, T.A.; Penlidis, A. A powerful estimation scheme with the error-in-variables model for nonlinear cases: Reactivity ratio estimation examples. Comput. Chem. Eng. 2013, 48, 200-208.

8. Kazemi, N.; Duever, T.A.; Penlidis, A. Reactivity ratio estimation from cumulative copolymer composition data. Macromol. React. Eng. 2011, 5, 385-403.

9. Brandrup, J.; Immergut, E.H.; Grulke, E.A. Polymer Handbook, 4th ed.; Wiley-Interscience: New York, NY, USA, 2003.

10. Kazemi, N.; Duever, T.A.; Penlidis, A. Investigations on azeotropy in multicomponent polymerizations. Chem. Eng. Technol. 2010, 33, 1841-1849.

11. Riahinezhad, M.; McManus, N.T.; Penlidis, A. Effect of monomer concentration and pH on reaction kinetics and copolymer microstructure of acrylamide/acrylic acid copolymer. Macromol. React. Eng. 2015, 9, 100-113.

12. Odian, G. Principles of Polymerization; Wiley-Interscience: Hoboken, NJ, USA, 2004.

13. Tidwell, P.W.; Mortimer, G.A. An improved method of calculating copolymerization reactivity ratios. J. Polym. Sci. Part A 1965, 3, 369-387.

14. Kazemi, N.; Duever, T.A.; Penlidis, A. Design of experiments for reactivity ratio estimation in multicomponent polymerizations using the error-in-variables approach. Macromol. Theory Simul. 2013, 22, 261-272.

15. Riahinezhad, M.; Kazemi, N.; McManus, N.; Penlidis, A. Effect of ionic strength on the reactivity ratios of acrylamide/acrylic acid (sodium acrylate) copolymerization. J. Appl. Polym. Sci. 2014, 131, 40949, doi:10.1002/app.40949.

16. Durmaz, S.; Okay, O. Acrylamide/2-acrylamido-2-methylpropane sulfonic acid sodium salt-based hydrogels: Synthesis and characterization. Polymer 2000, 41, 3693-3704.

17. Liu, Y.; Xie, J.-J.; Zhu, M.-F.; Zhang, X.-Y. A study of the synthesis and properties of AM/AMPS copolymer as superabsorbent. Macromol. Mater. Eng. 2004, 289, 1074-1078.

18. Pourjavadi, A.; Salimi, H.; Kurdtabar, M. Hydrolyzed collagen-based hydrogel with salt and pH-responsiveness properties. J. Appl. Polym. Sci. 2007, 106, 2371-2379.

19. Rosa, F.; Casquilho, M. Effect of synthesis parameters and of temperature of swelling on water absorption by a superabsorbent polymer. Fuel Process. Technol. 2012, 103, 174-177.

20. Sabhapondit, A.; Borthakur, A.; Haque, I. Characterization of acrylamide polymers for enhanced oil recovery. J. Appl. Polym. Sci. 2003, 87, 1869-1878.

21. Sabhapondit, A.; Borthakur, A.; Haque, I. Water soluble acrylamidomethyl propane sulfonate. Energy Fuels 2003, 17, 683-688.

22. Jamshidi, H.; Rabiee, A. Synthesis and characterization of acrylamide-based anionic copolymer and investigation of solution properties. Adv. Mater. Sci. Eng. 2014, 2014, 1-6.

23. Aggour, Y.A. Thermal degradation of copolymers of 2-acrylamido-2-methylpropanesulphonic acid with acrylamide. Polym. Degrad. Stab. 1994, 44, 71-73.

24. Billmeyer, F.W. Textbook of Polymer Science; John Wiley \& Sons, Inc.: New York, NY, USA, 1971.

25. Bune, Y.V.; Barabanova, A.; Bogachev, Y.S.; Gromov, V. Copolymerization of acrylamide with various water-soluble monomers. Eur. Polym. J. 1996, 33, 1313-1323. 
26. McCormick, C.L.; Chen, G.S. Water-soluble copolymers. IV. Random copolymers of acrylamide with sulfonated comonomers. J. Polym. Sci. Part A Polym. Chem. 1982, 20, 817-838.

27. Travas-Sejdic, J.; Easteal, A. Study of free-radical copolymerization of acrylamide with 2-acrylamido-2-methyl-1-propane sulphonic acid. J. Appl. Polym. Sci. 2000, 75, 619-628.

28. Abdel-Azim, A.-A.A.; Farahat, M.S.; Atta, A.M.; Abdel-Fattah, A.A. Preparation and properties of two-component hydrogels based on 2-acrylamido-2-methylpropane sulphonic acid. Polym. Adv. Technol. 1998, 9, 282-289.

29. Liao, L.; Yue, H.; Cui, Y. Crosslink polymerization kinetics and mechanism of hydrogels composed of acrylic acid and 2-acrylamido-2-methylpropane sulfonic acid. Chin. J. Chem. Eng. 2011, 19, 285-291.

30. Jie, Y.; Pan, Y.; Lu, Q.; Yang, W.; Gao, J.; Li, Y. Synthesis and swelling behaviors of $\mathrm{P}(\mathrm{AMPS}-\mathrm{co}-\mathrm{AAc})$ superabsorbent hydrogel produced by glow-discharge electrolysis plasma. Plasma Chem. Plasma Process. 2013, 33, 219-235.

31. Pourjavadi, A.; Seidi, F.; Salimi, H.; Soleyman, R. Grafted CMC/Silica gel superabsorbent composite: Synthesis and investigation of swelling behavior in various media. J. Appl. Polym. Sci. 2008, 108, 3281-3290.

32. Wang, Y.; Shi, X.; Wang, W.; Wang, A. Synthesis, characterization, and swelling behaviors of a pH-responsive CMC-g-poly(AA-co-AMPS) superabsorbent hydrogel. Turk. J. Chem. 2013, 37, 149-159.

33. Ryles, R.; Neff, R. Water-Soluble Polymers for Petroleum Recovery; Stahl, G., Schulz, D., Eds.; Springer: Anaheim, CA, USA, 1986.

34. Kazemi, N. Reactivity Ratio Estimation in Multicomponent Polymerization Systems Using the Error-in-Variables-Model (EVM) Framework. Ph.D. Thesis, Department of Chemical Engineering, University of Waterloo, Waterloo, ON, Canada, 2014.

(C) 2015 by the authors; licensee MDPI, Basel, Switzerland. This article is an open access article distributed under the terms and conditions of the Creative Commons Attribution license (http://creativecommons.org/licenses/by/4.0/). 